\title{
THE EVOLUTION OF EARLY AWARENESS AND ALERT METHODS AND SYSTEMS
}

In this theme section on early awareness and alert (EAA) systems and activities, we are pleased to present a series of articles covering the structure of EAA systems, their development and integration into decision making for the adoption and use of new and emerging health technologies, and the methods used by current networks, systems, and organizations.

It is difficult to imagine who would not be in favor of early intelligence about emerging health technologies that may benefit patients or improve the delivery of health care. The main advantages of such early intelligence include the opportunity to plan future investments, to decide where research and evaluation resources and efforts should be directed, and to ensure that health systems are able to embrace innovation in a sustainable way. Although the advantages of EAA systems and intelligence are clear, critics may highlight some disadvantages including the potential to stifle innovation and the introduction of a new barrier or hurdle to the adoption of new technologies. In addition, relying on information about risks and benefits arising early in a technology's life cycle to make decisions can be detrimental if the methods used and purpose of EAA intelligence is not understood.

Banta and Gelijns (1) were among the first to conclude that it is not satisfactory to react to technological developments only when confronted with their consequences. In the 1980s, they recommended a systematic approach to the identification and early assessment of new health technologies to provide advance notice to decision makers. They called this an early warning system. Further developments followed in the Netherlands, Sweden, and Denmark. It is not a coincidence, therefore, that the EuroScan International Network developed from discussions at two workshops held in Scandinavia in the 1990s, and its first Chair was from the Netherlands $(2 ; 3)$. These workshops identified areas of common interest in sharing information about emerging health technologies and in early identification, assessment, and adoption of these; this led to the formal establishment of the EuroScan collaboration in 1999.

The EuroScan International Network is now the leading global collaborative network that collects and shares information on innovative technologies in healthcare to support decision making and the adoption and use of effective, useful, and safe health-related technologies (www.euroscan.org.uk). The network is also the principal global forum for the sharing and development of methods for the early identification and early assessment of new and emerging technologies and their potential impact on health services and existing technologies. Although the name may indicate a European focus, EuroScan is open to organizations with EAA systems from around the world. Indeed Canada was a founder member, and the Australian and New Zealand network joined soon after. Members have also provided expertise on EAA methods, activities, systems and decision making on emerging health technologies to many countries including Argentina, Brazil, Chile, Jordan, Israel, Italy, Panama, Singapore, Thailand, and the United States, and can provide advice and support to organizations considering setting up EAA systems.

A key activity for EuroScan International Network members is the discussion of terminology used when referring to this activity and its principal methods. These discussions increase understanding and have significantly changed the terminology used to cover the whole activity from "horizon scanning" and "early warning" through "early identification and assessment" and finally to "early awareness and alert" (EAA) activities and systems. The reasons behind these changes include acknowledgement of the negative connotations of "warnings" when many emerging technologies should be welcomed and encouraged; the recognition that "horizon scanning" is only one (admittedly significant) component of EAA methods; and that effective dissemination of information to policy makers is vital to the whole activity. Throughout this theme section we have asked authors to use the "early awareness and alert" (EAA) terminology.

An effective EAA system identifies innovations in health technology likely to have a significant impact, and disseminates information relevant to the needs of the customer; timely information enables appropriate decision making (such as resource allocation), facilitates appropriate adoption and identifies further research requirements (4). Successful systems will have reliable connections and sources to identify new and emerging health technologies, filter and prioritize these technologies most likely to have a significant impact, and make an assessment of either potential impact or clinical and cost effectiveness. Information from EAA systems can be used to prioritize topics for further primary research; for in-depth assessment, review or meta-analysis; for service, manpower, financial or organizational planning and readiness; for the identification of technologies of low or no added value; or for 
producing and issuing guidance on use in relation to existing technology.

EAA activities were described in a special issue of this journal in 1998 (volume 14; issue 4), with papers contributed by authors from Sweden, the Netherlands, the United Kingdom and Denmark. In the following years the EuroScan International network was established and strengthened. Today it promotes EAA activities around the world and has signed memoranda of understanding with the World Health Organization, Health Technology Assessment International, and the International Network of Agencies for Health Technology Assessment (5). The authors, who also acted as associate editors of this themed section, have witnessed the evolution of EAA activities in the past decade, and supported many different EAA systems in their journeys to meet the needs of healthcare systems and decision makers.

Three papers presented in this section are good examples of the evolution and adaptation of EAA systems to context, including decentralized healthcare systems as in the case of Italy (Migliore et al., in this issue), federal countries such as Canada (Morrison et al., in this issue), and technology driven countries such as Israel (Tal et al., in this issue). Gutierrez-Ibarluzea et al. describe the jointly compiled methods toolkit for organizations considering setting up or reviewing a current EAA system, and outline some of the key differences and similarities in the methods used by comparing the EAA systems of EuroScan's members.

Future work to develop international EAA activities could be directed toward developing a consistent approach to the identification of each type of new and emerging health technology. This could be supplemented by relevant local sources and a more proactive collaboration with international and local producers, and local users of health technologies. Other means of prioritizing new technologies and assessing their potential for impact could be explored including consideration of the more active participation of stakeholders as proposed by Gallego et al. in this themed section. One of the key questions that EAA systems must answer is how to measure their impact. This has been partially addressed by Packer et al., but other types of evaluation, such as "return on investment" analysis should be also explored.

Although questions about overall impact remain, there is evidence that EAA activities and systems are spreading around the world. Moreover, the need for information about new and emerging technologies in their early stages of development is constant not only for EuroScan International Network member countries, but in countries with a shorter health technology assessment tradition such as South America (Pichon et al., in this issue) or Asia. EAA systems must also be aware of novel technologies such as regenerative medicines and techniques, in- formation and communication technologies, stratified and personalized health care, robotic and remote surgery; and of public health interventions including behavior change; these may challenge evaluation processes and put pressure on health services. Accordingly, our opinion is that EAA systems are guarantors of healthcare systems sustainability by supporting informed and accountable decisions based on the best available evidence along the life cycle of health technologies.

Claire Packer, BM, BS, FFPH

email: c.packer@bham.ac.uk

Director of the NIHR Horizon Scanning Centre

School of Health and Population Sciences

University of Birmingham,

Birmingham, United Kingdom

Iñaki Gutierrez-Ibarluzea, MS, PhD

Health Technology Assessment Technician

Osteba-Basque Office for HTA

Department of Health and Consumer Affairs

Vitoria-Gasteiz (Basque Country), Spain

Sue Simpson, BSc, PhD, MPH

Associate Director

NIHR Horizon Scanning Centre

School of Health and Population Sciences

University of Birmingham, Birmingham, United Kingdom

\section{CONFLICTS OF INTEREST}

Claire Packer's and Sue Simpson's institution receives a grant and travel expenses from UK National Institute for Health Research for horizon scanning activity. The other authors report they have no potential conflicts of interest

\section{REFERENCES}

1. Banta HD, Gelijns AC. The future and health care technology: Implication of a system for early identification. World Health Stat Q. 1994;47:140148.

2. Carlsson P, Jørgensen T, eds. European Workshop: scanning the horizon for emerging health technologies, 1997. Copenhagen: DSI and SBU; 1998.

3. Carlsson P, Jørgensen T. Scanning the horizon for emerging health technologies: Conclusions from a European workshop. Int J Technol Assess Health Care. 1998;14:695-706.

4. Murphy K, Packer C, Stevens A, Simpson S. Effective early warning systems for new and emerging health technologies: Developing an evaluation framework and an assessment of current systems. Int $J$ Technol Assess Health Care. 2007;23:324-330.

5. Simpson S, Packer C, Carlsson P, et al. Early identification and assessment of new and emerging health technologies: Actions, progress, and the future direction of an international collaboration - EuroScan. Int J Technol Assess Health Care. 2008;24:518-525. 